\title{
The Identification of Hereditary and Environmental Determinants of Frailty in a Cohort of UK Twins
}

\author{
Aideen C. M. Young, ${ }^{1}$ Karen Glaser, ${ }^{1}$ Timothy D. Spector ${ }^{2}$ and Claire J. Steves ${ }^{2}$ \\ ${ }^{1}$ Institute of Gerontology, Department of Global Health and Social Medicine, King's College London, London, UK \\ ${ }^{2}$ Department of Twin Research and Genetic Epidemiology, King's College London, London, UK
}

\begin{abstract}
Our study examines the contribution of genetic and environmental factors (both shared and unique) to frailty, measured using the Rockwood Frailty Index (FI) in a sample of twins from the St Thomas' UK Adult Twin Registry. The FI was based on 39 items of potential health deficit. Study participants were 3,375 volunteer adult twins (840 monozygotic and 802 dizygotic twin-pairs) 40.0-84.5 years old. First, we used structural equation modeling to estimate the relative contribution of genetics and of the shared and unique environment to variance in $\mathrm{Fl}$ adjusted for age. In a second analysis, multiple linear regression was used to examine variance in $\mathrm{Fl}$ as a function of father's occupational class (a component of shared environment and a measure of childhood socioeconomic status [SES]), adjusting for age, birth weight, marital status, and health behaviors (smoking, alcohol consumption, and physical activity). Statistical analyses were conducted using IBM SPSS ${ }^{\circledR}$ Version 22 software and Mx open source software. Findings showed that $45 \%$ (95\% confidence intervals [Cls] 30-53\%) of the inter-individual variation in $\mathrm{Fl}$ was heritable and $52 \%$ (95\% Cls $47-57 \%$ ) was due to the individual's unique environment. Multiple linear regression also showed a small but statistically significant inverse association between father's occupational class and $\mathrm{Fl}$, mediated by one's own educational attainment and birth weight. Our results indicate that frailty is both genetically and environmentally determined. Thus, its prevention and management call for a multifaceted approach that includes addressing deleterious environmental factors, some of which, like childhood SES, may act across the life course.
\end{abstract}

- Keywords: education, frailty, heritability, life course, occupation, socioeconomic status, SES, TwinsUK, Rockwood Frailty Index

Frailty is a multidimensional concept characterized by reduced resistance to stressors due to depleted physiological reserve. Its consequences are diverse and deleterious, and can include undernutrition and weight loss, as well as reduced strength and balance (Bergman et al., 2007). These, in turn, lead to a myriad of adverse sequelae such as falls, worsening mobility, hospitalization, and death. Frailty is increasingly recognized as an important geriatric condition whose identification and management are key to comprehensive geriatric care (Cesari et al., 2016; Gladman et al., 2016). A number of studies have identified genetic loci involved in the development of the frailty phenotype (Almeida et al., 2012; van den Beld et al., 1999; Walston et al., 2005), as well as environmental determinants including socioeconomic status (SES) and educational attainment (Alvarado et al., 2008; Andrew et al., 2008; Cramm \& Nieboer, 2013; Hoogendijk et al., 2014; Lang et al., 2009; Marshall et al., 2015; Moreira \& Lourenco, 2013; Peek et al., 2012; Romero-Ortuno, 2014; Szanton et al., 2010; Woo et al., 2005; Woods et al., 2005). However, to our knowl- edge, no study has yet examined both the genetic and environmental determinants of frailty in the same individuals. Thus, our study aims to extend our understanding of the determinants of frailty by examining its heritability and the impact of various behavioral and environmental factors in a population of UK twins.

The two principal instruments for the measurement of frailty are the Fried frailty phenotype (Fried \& Walston, 2003) and Rockwood's Frailty Index (FI). A FI is based on the number, rather than the type of one's health problems (Rockwood et al., 1994) and is calculated as the proportion of an array of possible deficits (Searle et al., 2008). Deficits

RECEIVED 25 April 2016; ACCEPTED 6 July 2016. First published online 10 October 2016.

ADDRess For CORRESPONDENCE: Aideen C. M. Young, Institute of Gerontology, Department of Global Health and Social Medicine, King's College London, London, UK. E-mail: aideen.young@kcl.ac.uk 
occur when damage at the subcellular level is unrepaired or unremoved. Eventually, in the absence of repair mechanisms to compensate for the damage, or an inability of intrinsic repair mechanisms to cope with requirements for repair, subcellular damage scales up to become macroscopically visible health impairment. In this deficit accumulation model of frailty, the more health deficits (whether signs, symptoms, diseases or disabilities) that a person has, the more likely they are to experience other adverse outcomes and to die (Rockwood et al., 2015). Thus, the FI predicts adverse health states, such as disability, hospitalization, dependency, institutionalization, and mortality (Clegg et al., 2013), and is also related to age (Theou et al., 2014).

Using data from a population of volunteer twins enrolled in the UK Adult Twin Registry (Moayyeri et al., 2013a; Spector \& Williams, 2006), we applied the classical twin model (Boomsma et al., 2002) to investigate the heritability of frailty as well as its association with the twins' unique and shared environment. The classical twin model derives its ability to separate genetic etiology of variance in a trait from environmental etiologies (both shared and unique) from the fact that monozygotic (MZ) twins share almost $100 \%$ of variable hereditary information encoded in DNA, whereas dizygotic (DZ) twins, on average, share only half (as for any non-twin siblings; Boomsma et al., 2002). Further, once the genetic effect on variance in a trait is known, the additional difference in variance between $\mathrm{MZ}$ and $\mathrm{DZ}$ twins allows the effects of their shared versus unique environment to be discerned. Although previous studies in twins have examined genetic variance in frailty, they have all used the Fried frailty phenotype (Dato et al., 2012; Miles, 1997), whereas we used Rockwood's FI in order to better understand the determinants of frailty when conceptualized as an 'accumulation of deficits' (Mitnitski et al., 2004).

In the second analysis reported here, the association between frailty and a specific element of shared environment - that of childhood SES, as embodied by father's occupational status - was selected for further examination. The aim of this additional analysis was to extend our understanding of the environmental determinants of frailty with a life-course approach. There is an extensive literature documenting how an array of childhood conditions, including SES, educational attainment and living arrangements, continue to have an impact on mortality and health into adulthood and old age (Hayward \& Gorman, 2004). If frailty in older age is shaped by environmental factors, it is of interest to understand if these persist across the life course. Hence, in this analysis, multivariate logistic regression analysis was used to determine the association between father's occupational status and frailty. Age, age at end of education, marital status, and the health behaviors of smoking, alcohol consumption, and level of physical exercise were included as covariates, as these have also been shown to be associated with the development of frailty (Etman et al., 2015; Hoogendijk et al., 2014; Hubbard et al., 2009; Leigh
\& Fries, 2002; Ortola et al., 2016; Strawbridge et al., 1998; Trevisan et al., 2016). Birth weight (self-reported) was also included as a covariate as there is some evidence that it is a robust indicator of health across the life course (United Nations Children's Emergency Fund [UNICEF] and World Health Organization [WHO], 2004). We believe this to be the first study to have applied the classical twin model (Boomsma et al., 2002) and standard epidemiological modeling in the same sample of adult twins.

\section{Methods}

\section{Subjects}

Study participants were volunteer adult twins from across the United Kingdom recruited into the St. Thomas' UK Adult Twin Registry since 1992 using national media campaigns. At this time, the registry consisted of approximately 12,000 volunteer MZ and DZ twins aged 18-103 years, as well as some parents and siblings (Moayyeri et al., 2013a; 2013b). Zygosity of subjects has been determined using a validated questionnaire (Peeters et al., 1998). Participants have previously been shown to be comparable to agematched population singletons in a wide range of characteristics, including bone mineral density, osteoarthritis, blood pressure, hypertensive drug use, height, history of hysterectomy and ovariectomy, menopausal status, and alcohol and tobacco consumption (Andrew et al., 2001).

\section{Measurements}

Multivariate logistic regression analysis used to construct a model describing the association between FI and father's occupational classification employed data from four self-report questionnaires - Q2, Q10, Q11A, and Q17D (the latter also known as the Healthy Ageing Twin Study [HATS]) - all collected between 1999 and 2010 by the TwinsUK registry (Moayyeri et al., 2013a; 2013b; Spector \& Williams, 2006) and covering a wide range of health and lifestyle issues (questionnaires can be found in full on the TwinsUK website at http://www.twinsuk.ac.uk/). See supplementary material, Table 1 , for questionnaire items used in the current analysis.

\section{Derivation of the Rockwood Frailty Index}

Thirty-nine items (see supplementary material, Table 2) in the domains of comorbid conditions, physical measures, biochemical measures, mental health, self-reported general health, disability, social functioning, polypharmacy, and pain that were collected via a questionnaire administered by a nurse practitioner and supplemented by physiological data and blood tests collected in HATS were used to derive the FI (Mitnitski et al., 2004) as described by Searle et al. (2008). Subjects who completed fewer than 20 domains were excluded from the analysis. The FI was a continuous variable with a value between 0 and 1 . 


\section{Operationalization of Variables for Multivariate Logistic Regression}

Father's occupational classification. The independent (predictor) variable of FI in multivariate logistic regression was childhood SES, measured using father's occupation as recalled by the respondent and categorized using the National Statistics Socioeconomic Classification (Office for National Statistics, 2005). The variable consisted of the following four categories: (1) modern and traditional professions and senior managers/administrators (referred to as 'professional'); (2) clerical and intermediate professions and middle and junior managers ('clerical'); (3) technical and craft professions ('technical'); and (4) semi-routine and routine manual professions ('manual'). A further binary variable was created consisting of technical and craft, semi-routine and routine manual categories (referred to as 'manual') and modern and traditional professions, senior managers/administrators, clerical and intermediate professions plus middle and junior managers (referred to as 'nonmanual').

Covariates. A binary categorical variable for age at end of education of $\leq 17$ years or $>17$ years was constructed using items from two questionnaires asking 'At what age did you finish full time education?' Where unavailable, this information was supplemented with responses as to which of 12 different educational qualifications a respondent had received (none, clerical, 1-4 O-levels, low vocational, 5+ O-levels, middle vocational, A-levels, nursing, teaching, higher vocational, university and other). Marital status was categorized as married, divorced/separated, never married or widowed. Using questionnaire responses on hours spent on various types of physical exercise and activity undertaken during leisure time in the previous week, a variable was constructed to describe a respondent's total physical activity level for the previous week as inactive, light, moderate, or vigorous. A categorical smoking variable was created with the categories never smoked; ex-smoker; and current smoker (see supplementary material, Table 1). Likewise, a variable with four possible values was constructed to describe alcohol consumption as none, $1-4,5-10$, or $\geq 11$ alcoholic drinks in the previous week. Age and birth weight were used as continuous variables. As the core sample was all female and $98 \%$ white, neither sex nor ethnic origin was retained as covariates in this analysis.

\section{Statistical Analysis}

Transformation of the Rockwood frailty index. A square root (sqrt) transformation was applied to the FI to provide a distribution that was close to normal (skewness statistic with standard error $[S E]=0.370[0.042]$; kurtosis statistic $[S E]=0.185[0.084])$. This transformed variable is denoted as sqrt $[\mathrm{FI}]$.
Standard structural equation modeling: the classical twin model. For our first analysis, standard structural equation modeling, as used in the classical twin model (Boomsma et al., 2002), was used to estimate the relative contribution of genetics and of shared and unique environment to the variance in FI adjusted for age, using MX open source software (Neale et al., 1994).

Multivariate logistic regression analysis: father's occupational classification. In our second analysis, standard hierarchical multiple linear regression techniques were used to explain variance in sqrt[FI] as a function of father's occupational classification - adjusting for age and other covariates. Tests for outliers and multicollinearity were conducted prior to analysis. All statistical tests were one-sided and associations were deemed statistically significant with $p$ $<$.05. All statistics were conducted using IBM SPSS ${ }^{\circledR}$ Version 22 software.

Additional path analysis was performed to examine any moderating and mediating influences of covariates on the proposed effect of father's occupational classification on FI. Mediation analysis was conducted using the PROCESS plug-in tool for SPSS (http://afhayes.com/spsssas-and-mplus-macros-and-code.html) (Preacher \& Hayes, 2004).

\section{Results}

\section{Study Participants}

The core dataset comprised 3,375 participants (all female and $98 \%$ white) with FI data. Participants were 1,644 twin pairs and 87 respondents with no twin in the dataset. Of the 1,644 twin pairs, 841 were MZ, 802 were DZ, and one was of unknown zygosity. Table 1 shows the key sample characteristics and the mean FI for each of the variables considered. The age of respondents ranged from 40.0 to 84.5 years with a mean (standard deviation $[S D]$ ) age of 59.12 (9.3) years. Self-reported birth weight ranged from 0.793 to $4.129 \mathrm{~kg}$ with a mean $(S D)$ of $2.382(0.578) \mathrm{kg}(n=2,804)$. The distribution of respondents by father's occupational class ranged from $17.7 \%$ for those with clerical fathers to $33.7 \%$ for those with professional fathers.

\section{Frailty: Descriptive Statistics and Heritability}

In this sample, the FI followed the expected gamma distribution (Figure 1), with a maximum value of 0.67 consistent with previous studies (Searle et al., 2008). The mean (SD) FI of the total sample was $0.132(0.105)$ with 25 th, 50 th, and 75 th quartiles of $0.059,0.105$, and 0.178 , respectively. There was a significant relationship between FI and age (standardized beta of $0.035 ; p<.001$ ) (Figure 2).

The mean correlation in FI scores between the twins of the $\mathrm{MZ}$ twin pairs was 0.47 , compared to 0.27 for the twins of the DZ twin pairs, indicating greater similarity in the frailty scores of the MZ than DZ twins. Consistent with this, 
TABLE 1

Mean (SD) FI by Category of Variables and $p$ Value for Test of Trend with FI

\begin{tabular}{|c|c|c|c|}
\hline $\begin{array}{l}\text { Variable } \\
\quad \text { Category }\end{array}$ & Number (\%) & Mean $(S D) \mathrm{FI}$ & $p$ value for test of trend with $\mathrm{FI}$ \\
\hline $\begin{array}{l}\text { Age } \\
\quad \leq 50 \text { years } \\
>50 \text { and } \leq 60 \text { years } \\
>60 \text { and } \leq 70 \text { years } \\
>70 \text { years }\end{array}$ & $\begin{array}{l}592(17.5) \\
1,148(34.0) \\
1,191(35.3) \\
444(13.2)\end{array}$ & $\begin{array}{l}0.094(0.083) \\
0.117(0.099) \\
0.140(0.101) \\
0.198(0.119)\end{array}$ & $<.001^{\ddagger}$ \\
\hline $\begin{array}{l}\text { Zygosity } \\
\text { MZ } \\
\text { DZ }\end{array}$ & $\begin{array}{l}1,720(51.0) \\
1,653(49.0)\end{array}$ & $\begin{array}{l}0.130(0.104) \\
0.135(0.105)\end{array}$ & Not significant \\
\hline $\begin{array}{l}\text { Age at end of education } \\
\quad \leq 17 \text { years } \\
>17 \text { years }\end{array}$ & $\begin{array}{l}2,154(63.8) \\
1,113(33.0)\end{array}$ & $\begin{array}{l}0.144(0.111) \\
0.109(0.084)\end{array}$ & $<.001$ \\
\hline $\begin{array}{l}\text { Marital status } \\
\text { Married } \\
\text { Never married } \\
\text { Divorced/separated } \\
\text { Widowed }\end{array}$ & $\begin{array}{l}2,255(66.8) \\
339(10.0) \\
435(12.9) \\
296(8.8)\end{array}$ & $\begin{array}{l}0.126(0.100) \\
0.134(0.104) \\
0.131(0.111) \\
0.172(0.114)\end{array}$ & $<.001$ \\
\hline $\begin{array}{l}\text { Exercise level } \\
\text { Inactive } \\
\text { Light activity } \\
\text { Moderate activity } \\
\text { Vigorous activity }\end{array}$ & $\begin{array}{l}841(24.9) \\
810(24.0) \\
1,121(33.2) \\
564(16.7)\end{array}$ & $\begin{array}{l}0.178(0.129) \\
0.138(0.097) \\
0.111(0.085) \\
0.095(0.079)\end{array}$ & $<.001$ \\
\hline $\begin{array}{l}\text { Smoking history } \\
\text { Never-smoker } \\
\text { Ex-smoker } \\
\text { Current smoker }\end{array}$ & $\begin{array}{l}1,794(53.2) \\
1,088(32.2) \\
455(13.5)\end{array}$ & $\begin{array}{l}0.127(0.101) \\
0.129(0.102) \\
0.160(0.120)\end{array}$ & $<.001$ \\
\hline $\begin{array}{l}\text { Alcohol consumption in previous week } \\
\text { No drinks } \\
1-4 \text { drinks } \\
5-10 \text { drinks } \\
\geq 11 \text { drinks }\end{array}$ & $\begin{array}{l}1,074(31.8) \\
1,160(34.4) \\
706(20.9) \\
386(11.4)\end{array}$ & $\begin{array}{l}0.152(0.114) \\
0.121(0.093) \\
0.117(0.100) \\
0.123(0.095)\end{array}$ & $<.001$ \\
\hline $\begin{array}{l}\text { Father's occupational classification } \\
\text { Professional } \\
\text { Clerical } \\
\text { Technical } \\
\text { Manual }\end{array}$ & $\begin{array}{l}831(24.6) \\
437(12.9) \\
575(17.0) \\
625(18.5)\end{array}$ & $\begin{array}{l}0.119(0.093) \\
0.127(0.099) \\
0.136(0.105) \\
0.149(0.112)\end{array}$ & $<.001$ \\
\hline
\end{tabular}

Note: ${ }^{\dagger} \%$ of total number of cases $(n=3,375)$.

"statistical test with age as a continuous variable; $\mathrm{FI}=$ Frailty Index.

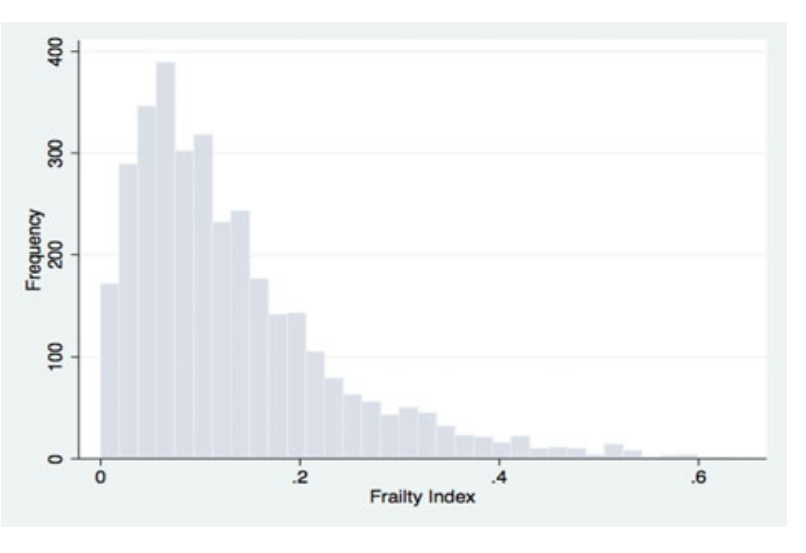

FIGURE 1

(Colour online) Distribution of frailty indices.

modeling revealed that $45 \%$ (95\% confidence intervals [CIs] of $30-53 \%$ ) of the inter-individual variation in FI was attributable to additive genetic effects and 52\% (95\% CIs 47-

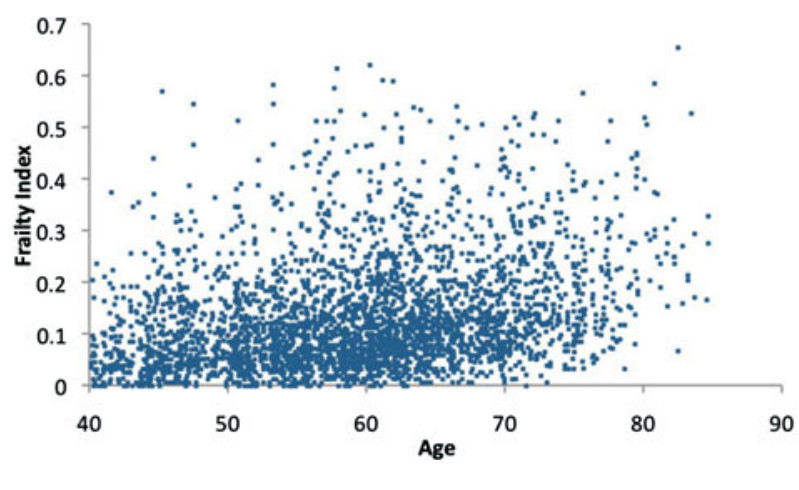

FIGURE 2

(Colour online) Frailty index by chronological age.

$57 \%$ ) to the respondents' unique environment. In this analysis, environmental factors that were shared by twins had a non-significant effect on FI (3\%; 95\% CIs 0-16\%). 
TABLE 2

Results of Hierarchical Multiple Regression Showing Unstandardized Beta Coefficients (Reference Groups are Indicated)

\begin{tabular}{|c|c|c|c|c|c|}
\hline & Model 1 & Model 2 & Model 3 & Model 4 & Model 5 \\
\hline$R^{2}$ & 0.119 & 0.125 & 0.132 & 0.204 & 0.206 \\
\hline$R^{2}$ change & & 0.007 & 0.008 & 0.075 & 0.003 \\
\hline Constant & 0.099 & 0.124 & 0.117 & 0.172 & 0.182 \\
\hline \multicolumn{6}{|l|}{ Variable } \\
\hline Age & $0.005^{* * *}$ & $0.005^{* * *}$ & $0.005^{* * *}$ & $0.005^{* * *}$ & $0.005^{* * *}$ \\
\hline Birth weight & $-0.024^{* * *}$ & $-0.023^{* * *}$ & $-0.023^{* * *}$ & $-0.020^{* * *}$ & $-0.020^{* * *}$ \\
\hline \multicolumn{6}{|l|}{$\begin{array}{l}\text { Age at end of education } \\
\leq 17 \text { years (reference) }\end{array}$} \\
\hline$>17$ years & & $-0.025^{* * *}$ & $-0.027^{* * *}$ & $-0.015^{*}$ & -0.011 (ns) \\
\hline \multicolumn{6}{|l|}{ Marital status } \\
\hline Never married & & & $0.042^{* * *}$ & $0.029 * *$ & $0.028^{* *}$ \\
\hline Divorced/separated & & & 0.015 (ns) & 0.014 (ns) & 0.014 (ns) \\
\hline Widowed & & & $0.018(\mathrm{~ns})$ & 0.014 (ns) & 0.013 (ns) \\
\hline \multicolumn{6}{|l|}{ Health behaviors } \\
\hline \multicolumn{6}{|l|}{$\begin{array}{l}\text { Exercise level } \\
\text { Inactive (reference) }\end{array}$} \\
\hline Light activity & & & & $-0.038^{* * *}$ & $-0.038^{* * *}$ \\
\hline Moderate activity & & & & $-0.063^{* * *}$ & $-0.062^{* * *}$ \\
\hline Vigorous activity & & & & $-0.087^{* * *}$ & $-0.086^{* * *}$ \\
\hline \multicolumn{6}{|l|}{ Smoking history } \\
\hline Ex-smoker & & & & 0.011 (ns) & 0.011 (ns) \\
\hline Current smoker & & & & $0.047^{* * *}$ & $0.047^{* * *}$ \\
\hline \multicolumn{6}{|c|}{ Alcohol consumption in previous week } \\
\hline 1-4 drinks & & & & $-0.030^{* * *}$ & $-0.030^{* * *}$ \\
\hline 5-10 drinks & & & & $-0.040^{* * *}$ & $-0.039^{* * *}$ \\
\hline$\geq 11$ drinks & & & & $-0.034^{* * *}$ & $-0.033^{* * *}$ \\
\hline \multicolumn{6}{|c|}{$\begin{array}{l}\text { Father's professional classification } \\
\text { Manual (reference) }\end{array}$} \\
\hline Professional & & & & & $-0.017^{*}$ \\
\hline Clerical & & & & & $-0.020^{*}$ \\
\hline Technical & & & & & -0.012 (ns) \\
\hline
\end{tabular}

\section{Association Between Frailty and Father's Occupational Classification}

In the second analysis, standard hierarchical multiple linear regression was conducted to construct a model to describe the relationship between a specific element of shared environment - father's occupational classification - and FI. Covariates were tested in blocks in a logical order, following a life-course conceptualization as follows: (1) the intrinsic characteristics of birth weight and age; then the mid-life characteristics of: (2) age at end of education and (3) marital status; (4) concurrent health behaviors of physical exercise, smoking and alcohol consumption; and (5) father's occupational classification. As father's occupational classification was the key predictor variable, this was included last in the model.

Overall, the regression model comprising a number of specific unique and shared environmental characteristics explained $20.6 \%$ of the observed variance in sqrt[FI] (Table 2). Father's occupational classification was seen to make a small, though significant contribution to the observed variance in sqrt [FI] in the final regression model. Thus, a professional or clerical occupational status for one's father (as opposed to the reference manual status) resulted in a small $\left(R^{2}\right.$ change of $\left.0.3 \%\right)$ but statistically significant $(p$ $<.05)$ reduction in mean sqrt[FI]. The largest contributors to variance in FI in the regression model were age and birth weight (Model 1; 11.9\%) followed by the health behaviors (Model 4; 7.5\%) of exercise, smoking, and alcohol consumption, which were statistically significant in the final model (with the exception that being an ex-smoker rather than having never smoked had no effect). The only marital status that was significant in the final regression model was the never-married status: people who had never married had a mean sqrt[FI] which was 0.028 higher than that of married people. As health behaviors and marital status are aspects of one's unique environment, these results are consistent with those of the standard structural equation modeling described above. In contrast, the fact that father's occupational classification, part of one's shared environmental characteristics, was significant in the 
logistic regression analysis, appears to run counter to the results of standard structural equation modeling described above, which did not find a significant effect of shared environment in its totality.

\section{Testing for Moderation and Mediation Relationships}

To further understand the pathway linking father's occupational classification and sqrt[FI], moderation and mediation analyses were conducted. Marital status, physical exercise, smoking history, and alcohol consumption had no statistically significant moderating effect on the observed effect of father's occupational class on frailty and can therefore be said to exert a direct effect on FI.

However, mediation analysis revealed that father's occupational classification exerts its effect on sqrt[FI] via birth weight and (separately) via age at end of education. The total effect of father's occupational classification (now considered as a binary, categorical variable - either manual or non-manual) on sqrt[FI] was $-0.0329(p<.0001)$; the direct (unmediated) effect was $-0.0310(p<.0001)$, leaving a small but statistically significant indirect effect of -0.0019 (95\% CIs of $-0.0037,-0.0006)$ that is the part of the effect of father's occupational classification on frailty that is mediated by birth weight. Similarly, in mediation analysis evaluating the role of age at end of education (used as a continuous rather than a binary variable), the total effect of father's occupational classification on sqrt[FI] was -0.0291 $(p<.0001)$; the direct (unmediated) effect was -0.0234 ( $p=$ $.0001)$, leaving a statistically significant indirect effect of -0.0057 (95\% CIs of $-0.0098,-0.0030)$ that is the part of the effect of father's occupational classification on frailty that is mediated by an individual's own educational attainment.

\section{Discussion}

To our knowledge, this is the first study to have applied the classical twin model (Boomsma et al., 2002) and standard epidemiological modeling in the same sample of adult twins. It is also the first to examine the heritability of frailty using Rockwood's FI. Genetic variance in frailty has been evaluated in previous studies in twins but using the Fried frailty phenotype (Dato et al., 2012; Miles, 1997). In those studies, heritability was found to explain less than half of the variance in frailty, consistent with the value of $45 \%$ found here (by comparison, longevity is just $25 \%$ inherited; Christensen et al., 2006). Hence, genetic factors (of which there are likely to be many) contribute significantly to frailty. Moreover, the similarity between our finding and those of the previous studies suggests that Rockwood's FI and the Fried frailty phenotype capture similar measures of frailty. That there is a large heritable component to frailty is supported by the fact that the regression model, incorporating a number of selected, shared (viz. father's occupational classification) and unique (viz. education, marital status, and health behaviors) environmental factors (plus age and birth weight), accounted for just $20.6 \%$ of the variance in sqrt[FI].

Structural equation modeling found that $52 \%$ of the variance in frailty was the result of factors in the respondent's unique environment, that is, environmental factors not shared with the respondent's twin. Multivariate logistic regression also found that specific aspects of the unique environment - namely, education, marital status, and health behaviors - had a significant association with frailty. However, structural equation modeling also found that shared environment, in its totality, had a non-significant impact on frailty, while multivariate logistic regression analysis found a statistically significant, inverse association between father's occupational classification in childhood and frailty.

There are a number of possible explanations for this apparent contradiction. First, the totality of 'shared environment' encompasses many other factors besides father's occupational classification and, although it was significant, the association of father's occupational classification with later life frailty was small. Indeed, it was smaller than the associations between frailty and all the other unique environmental effects incorporated into the model; thus, a person whose father had a professional occupation had a mean sqrt[FI] that was just 0.017 units less than that of someone whose father had been a manual worker. Also, twins may experience the same early life SES factors differently, in which case they are not shared but instead contribute to the unique environmental component.

Another important consideration is that the analyses conducted did not account for potential gene $\times$ environment interactions, but rather treated genetic and environmental factors as separate and distinct. However, in so-called epigenetic processes, environmental factors can cause chemical modification of the DNA, most notably changes in levels of DNA methylation, that in turn, alter gene expression. Importantly, these modifications do not involve an alteration in DNA sequence but do confer an additional layer of information within the genome (Bagot \& Meaney, 2010), that is itself heritable (Burdge et al., 2007). DNA methylation is characteristic of the aging process so much so that it acts as an 'epigenetic clock' that generally correlates with chronological age across the life course. Thus, aging has an impact on the processes of DNA methylation, but, importantly, changes in DNA methylation can also affect the aging process. Indeed, studies have shown that low childhood and adult SES (Needham et al., 2015) and adverse environmental factors and lifestyle (Fraga et al., 2005) are associated with changes in levels of DNA methylation, thus accelerating the epigenetic clock and one's biological age.

In turn, the epigenetic clock has been shown to be associated with measures of health, including markers of mental and physical fitness, in a population of older people (Marioni et al., 2015). Associations have also been seen between 
frailty and both global (Bellizzi et al., 2012) and locusspecific (Collerton et al., 2014) methylation levels (Breitling et al., 2016).

Hence, it is possible that SES, in the form of father's occupational status, exerts its effects on frailty via an epigenetic interaction. Thus, in the current study, father's occupational status had a statistically significant association with frailty as shown by the results of multiple regression, but it may be that no effect for shared environment could be discerned in structural equation modeling because the analysis did not account for those epigenetic interactions.

Taken together, these results suggest that variance in frailty is predominantly genetically determined and highly age-dependent, but that it is also shaped by environmental factors, especially one's own health behaviors and characteristics such as marital status and education. Moreover, there is a small effect of childhood SES, as measured by father's occupational classification, which acts across the life course. This is in accordance with a large body of literature demonstrating that the effects of childhood disadvantage persist into adulthood (Adler \& Stewart, 2010; Bengtsson \& Lindstrom, 2000; Crimmins \& Cambois, 2003) and lend support to a life-course approach to health. However, the effect seen is mediated through educational attainment, highlighting the importance of education as a pathway to countering familial disadvantage. These results are consistent with theories of frailty expounded by Rockwood and coworkers in which a high deficit count does not necessarily signify a high absolute risk to an individual, but rather a relative increase in risk, as risk can be exacerbated by factors such as social vulnerability (Rockwood et al., 2015) or mitigated by protective factors including education, exercise, economic status, not smoking, social engagement, and urban living (Wang et al., 2014).

This study had a number of limitations. First, the study sample was comprised of volunteers. This is a necessary aspect of the TwinsUK initiative as twins can only be enrolled voluntarily in the United Kingdom, but it may result in nonrepresentativeness, as higher SES groups are known to be more likely to participate in voluntary studies than lower SES groups (Freudenstein et al., 2001; Goldberg et al., 2001; Hoeymans et al., 1998; Purdie et al., 2002). In addition, the final core sample, comprising respondents for whom there was an FI measurement, was entirely female and almost entirely white. Of note too, although about one third of twins in the United Kingdom are MZ and the rest DZ, this sample was made up of approximately 50\% MZ and 50\% DZ twins. Although participants have previously been shown to be comparable to age-matched population singletons across a wide range of physiological characteristics, as well as alcohol and tobacco consumption (Andrew et al., 2001), caution is needed in extrapolating the results of this study to the population as a whole.

There are also a number of well-known limitations to the classical twin model. First, recent evidence shows that
MZ twins may not share $100 \%$ of their variable DNA as has been assumed (Bruder et al., 2008) which would lead to underestimates of heritability. Second, the classical twin model assumes an equivalent shared environment for $\mathrm{MZ}$ and DZ twins. Although numerous studies have broadly upheld this assumption (Derks et al., 2006; Kendler et al., 1993; Scarr, 1968), some have challenged it, though only for subjective traits, for which $\mathrm{MZ}$ twins may rate themselves more similarly than DZ twins (Richardson \& Norgate, 2005; Tishler \& Carey, 2007). Notably, if MZ twins shared environment more than DZ twins, heritability estimates would be inflated. Third, the classical twin model assumes no assortive mating on the traits of interest, an assumption that may not hold in considerations of SES. However, assortive mating on SES would likely lead to an underestimate of heritability of frailty and an overestimate of shared environment, as DZ twins would share more than half of their variable hereditary information, an observation that was clearly not seen. In addition, the classical twin model assumes that there are no non-additive genetic effects. In practice, such effects are present only when dominance at a key locus exists, or when two loci interact. As frailty is likely to be a highly polygenetic trait, violation of this assumption appears unlikely. A further limitation expounded upon above is that the analyses did not account for possible epigenetic pathways.

One must also note the study's reliance on subject's recall of both birth weight and father's occupation. Recall bias is a common and significant challenge in social science research. One study has reported that agreement between social class of father recalled in adulthood and that measured in early life is 'moderate' (Batty et al., 2005). The fact that the current study is comprised of twins provided a method of checking consistency of responses. In fact, $76 \%$ of twins gave identical responses to the question about their father's occupation, similar to the proportions seen in a previous study (Krieger et al., 1998). In general, however, it seems likely that associations between childhood social class based on adult recall of parental occupation and health outcomes will underestimate real effects.

Whether childhood SES has a significant effect on frailty in this twin sample because they are relatively young and whether the effects of childhood SES on frailty will dissipate as the population gets older and childhood events become more distant remains unresolved. The TwinsUK study will continue to evaluate this sample as they age so it will be possible to see whether the effects of father's occupational classification on frailty dissipate as respondents become older and whether conditions in adulthood become more important for frailty. If so, this would indicate that more distant experiences and events may become secondary to more proximal ones across the life course, as has been found by others (Herr et al., 2015). 


\section{Conclusions}

Variance in frailty in a sample of twins, aged from 40.0 to 84.5 years, enrolled in the St. Thomas' UK Adult Twin Registry, was seen to be approximately equally attributable to heritable factors and those inherent in one's unique environment. Age was significantly and directly associated with frailty, while being married, never smoking, drinking alcohol, and engaging in physical exercise were inversely associated. In addition, a small but significant association was seen between frailty and father's occupational classification, mediated by birth weight and an individual's own educational attainment.

The advent of frailty in an older person has serious health implications, but if those most likely to develop frailty can be identified it may be possible to devise strategies to prevent progression into frailty. With aging populations seen as a global challenge, such strategies may enable the extension of healthy life, reduce dependence, improve quality of life, and reduce burden on governments. Our study demonstrates that prevention and management of this complex, multidimensional condition calls for a multifaceted approach that includes addressing deleterious environmental factors, some of which may act across the life course.

\section{Financial Support}

This work was supported by the Wellcome Trust (T.S., grant number 081878/Z/06/Z).

\section{Conflict of Interest}

None.

\section{Ethical Standards}

The authors assert that all procedures contributing to this work comply with the ethical standards of the relevant national and institutional committees on human experimentation and with the Helsinki Declaration of 1975, as revised in 2008. All respondents provided informed consent that was approved by St Thomas' Hospital Research Ethics Committee.

\section{Supplementary Material}

To view supplementary material for this article, please visit http://dx.doi.org/10.1017/thg.2016.72.

\section{References}

Adler, N. E., \& Stewart, J. (2010). Health disparities across the lifespan: Meaning, methods, and mechanisms. Annals of the New York Academy of Sciences, 1186, 5-23.

Almeida, O. P., Norman, P. E., Van Bockxmeer, F. M., Hankey, G. J., \& Flicker, L. (2012). CRP 1846G >A polymorphism increases risk of frailty. Maturitas, 71, 261-266.

Alvarado, B. E., Zunzunegui, M. V., Beland, F., \& Bamvita, J. M. (2008). Life course social and health conditions linked to frailty in Latin American older men and women. The Journals of Gerontology. Series A, Biological Sciences and Medical Sciences, 63, 1399-1406.

Andrew, M. K., Mitnitski, A. B., \& Rockwood, K. (2008). Social vulnerability, frailty and mortality in elderly people. PLoS One, 3, e2232.

Andrew, T., Hart, D. J., Snieder, H., de Lange, M., Spector, T. D., \& MacGregor, A. J. (2001). Are twins and singletons comparable? A study of disease-related and lifestyle characteristics in adult women. Twin Research, 4, 464-477.

Bagot, R. C., \& Meaney, M. J. (2010). Epigenetics and the biological basis of gene $\mathrm{x}$ environment interactions. Journal of the American Academy of Child and Adolescent Psychiatry, 49, 752-771.

Batty, G. D., Lawlor, D. A., Macintyre, S., Clark, H., \& Leon, D. A. (2005). Accuracy of adults' recall of childhood social class: Findings from the Aberdeen children of the 1950s study. Journal of Epidemiology and Community Health, 59, 898-903.

Bellizzi, D., D’Aquila, P., Montesanto, A., Corsonello, A., Mari, V., Mazzei, B., ... Passarino, G. (2012). Global DNA methylation in old subjects is correlated with frailty. Age (Dordrecht), 34, 169-179.

Bengtsson, T., \& Lindstrom, M. (2000). Childhood misery and disease in later life: The effects on mortality in old age of hazards experienced in early life, southern Sweden, 17601894. Population Studies (Cambridge), 54, 263-277.

Bergman, H., Ferrucci, L., Guralnik, J., Hogan, D. B., Hummel, S., Karunananthan, S., \& Wolfson, C. (2007). Frailty: An emerging research and clinical paradigm - issues and controversies. The Journals of Gerontology Series A: Biological Sciences and Medical Sciences, 62, 731-737.

Boomsma, D., Busjahn, A., \& Peltonen, L. (2002). Classical twin studies and beyond. Nature Reviews Genetics, 3, 872882.

Breitling, L. P., Saum, K. U., Perna, L., Schöttker, B., Holleczek, B., \& Brenner, H. (2016). Frailty is associated with the epigenetic clock but not with telomere length in a German cohort. Clinical Epigenetics, 8, 21.

Bruder, C. E., Piotrowski, A., Gijsbers, A. A., Andersson, R., Erickson, S., Diaz de Stahl, T., ... Dumanski, J. P. (2008). Phenotypically concordant and discordant monozygotic twins display different DNA copy-number-variation profiles. American Journal of Human Genetics, 82, 763-771.

Burdge, G. C., Slater-Jefferies, J., Torrens, C., Phillips, E. S., Hanson, M. A., \& Lillycrop, K. A. (2007). Dietary protein restriction of pregnant rats in the F0 generation induces altered methylation of hepatic gene promoters in the adult male offspring in the F1 and F2 generations. British Journal of Nutrition, 97, 435-439.

Cesari, M., Marzetti, E., Thiem, U., Perez-Zepeda, M. U., Abellan Van Kan, G., Landi, F., ... Bernabei, R. (2016). The geriatric management of frailty as paradigm of 'The end of the disease era'. European Journal of Internal Medicine, 31, $11-14$.

Christensen, K., Johnson, T. E., \& Vaupel, J. W. (2006). The quest for genetic determinants of human longevity: Challenges and insights. Nature Reviews Genetics, 7, 436-448. 
Clegg, A., Young, J., Iliffe, S., Rikkert, M. O., \& Rockwood, K. (2013). Frailty in elderly people. Lancet, 381, 752-762.

Collerton, J., Gautrey, H. E., van Otterdijk, S. D., Davies, K., Martin-Ruiz, C., von Zglinicki, T., ... Strathdee, G. (2014). Acquisition of aberrant DNA methylation is associated with frailty in the very old: Findings from the Newcastle 85+ study. Biogerontology, 15, 317-328.

Cramm, J. M., \& Nieboer, A. P. (2013). Relationships between frailty, neighborhood security, social cohesion and sense of belonging among community-dwelling older people. Geriatrics and Gerontology International, 13, 759-763.

Crimmins, E. M., \& Cambois, E. (2003). Social inequalities in life expectancy. In J. M. Robine, C. Jagger, C. D. Mathers, E. M. Crimmins \& R. M. Suzman (Eds.), Determining health expectancies (pp. 111-126). Chichester, UK: John Wiley and Sons.

Dato, S., Montesanto, A., Lagani, V., Jeune, B., Christensen, K., \& Passarino, G. (2012). Frailty phenotypes in the elderly based on cluster analysis: A longitudinal study of two Danish cohorts. Evidence for a genetic influence on frailty. Age (Dordrecht), 34, 571-582.

Derks, E. M., Dolan, C. V., \& Boomsma, D. I. (2006). A test of the equal environment assumption (EEA) in multivariate twin studies. Twin Research and Human Genetics, 9, 403411.

Etman, A., Kamphuis, C. B., van der Cammen, T. J., Burdorf, A., \& van Lenthe, F. J. (2015). Do lifestyle, health and social participation mediate educational inequalities in frailty worsening? European Journal of Public Health, 25, 345-350.

Fraga, M. F., Ballestar, E., Paz, M. F., Ropero, S., Setien, F., Ballestar, M. L., ... Esteller, M. (2005). Epigenetic differences arise during the lifetime of monozygotic twins. Proceedings of the National Academy of Sciences of the United States of America, 102, 10604-10609.

Freudenstein, U., Arthur, A. J., Matthews, R. J., \& Jagger, C. (2001). Community surveys of late-life depression: Who are the non-responders? Age and Ageing, 30, 517-521.

Fried, L. P., \& Walston, J. M. (2003). Frailty and failure to thrive. In W. R. Hazzard, J. P. Blass, J. Halter \& J. Ouslander (Eds.), Principles of geriatric medicine and gerontology (5th ed., pp. 1387-1402). New York: McGraw-Hill Professional.

Gladman, J. R., Conroy, S. P., Ranhoff, A. H., \& Gordon, A. L. (2016). New horizons in the implementation and research of comprehensive geriatric assessment: Knowing, doing and the 'know-do' gap. Age and Ageing, 45, 194-200.

Goldberg, M., Chastang, J. F., Leclerc, A., Zins, M., Bonenfant, S., Bugel, I., ... Imbernon, E. (2001). Socioeconomic, demographic, occupational, and health factors associated with participation in a long-term epidemiologic survey: A prospective study of the French GAZEL cohort and its target population. American Journal of Epidemiology, 154, 373-384.

Hayward, M. D., \& Gorman, B. K. (2004). The long arm of childhood: The influence of early-life social conditions on men's mortality. Demography, 41, 87-107.

Herr, M., Robine, J. M., Aegerter, P., Arvieu, J. J., \& Ankri, J. (2015). Contribution of socioeconomic position over life to frailty differences in old age: Comparison of life-course models in a French sample of 2350 old people. Annals of Epidemiology, 25, 674-680.

Hoeymans, N., Feskens, E. J., Van Den Bos, G. A., \& Kromhout, D. (1998). Non-response bias in a study of cardiovascular diseases, functional status and self-rated health among elderly men. Age and Ageing, 27, 35-40.

Hoogendijk, E. O., van Hout, H. P., Heymans, M. W., van der Horst, H. E., Frijters, D. H., Broese van Groenou, M. I., ... Huisman, M. (2014). Explaining the association between educational level and frailty in older adults: Results from a 13-year longitudinal study in the Netherlands. Annals of Epidemiology, 24, 538-544.

Hubbard, R. E., Searle, S. D., Mitnitski, A., \& Rockwood, K. (2009). Effect of smoking on the accumulation of deficits, frailty and survival in older adults: A secondary analysis from the Canadian study of health and aging. The Journal of Nutrition, Health and Aging, 13, 468-472.

Kendler, K. S., Neale, M. C., Kessler, R. C., Heath, A. C., \& Eaves, L. J. (1993). A test of the equal-environment assumption in twin studies of psychiatric illness. Behavior Genetics, 23, 21-27.

Krieger, N., Okamoto, A., \& Selby, J. V. (1998). Adult female twins' recall of childhood social class and father's education: A validation study for public health research. American Journal of Epidemiology, 147, 704-708.

Lang, I. A., Hubbard, R. E., Andrew, M. K., Llewllyn, D. J., Melzer, D., \& Rockwood, K. (2009). Neighborhood deprivation, individual socioeconomic status, and frailty in older adults. Journal of the American Geriatric Society, 57, 17761780.

Leigh, J. P., \& Fries, J. F. (2002). Frailty and education in the Hispanic health and nutrition examination survey. Journal of Health Care for the Poor and Underserved, 13, 112-127.

Marioni, R. E., Shah, S., McRae, A. F., Ritchie, S. J., MunizTerrera, G., Harris, S. E., ... Deary, I. J. (2015). The epigenetic clock is correlated with physical and cognitive fitness in the Lothian Birth Cohort 1936. International Journal of Epidemiology, 44, 1388-1396.

Marshall, A., Nazroo, J., Tampubolon, G., \& Vanhoutte, B. (2015). Cohort differences in the levels and trajectories of frailty among older people in England. Journal of Epidemiology and Community Health, 69, 316-321.

Miles, T. P. (1997). Population-based, genetically informative sample for studies of physical frailty and aging: Black elderly twin study. Human Biology, 69, 107-120.

Mitnitski, A. B., Song, X., \& Rockwood, K. (2004). The estimation of relative fitness and frailty in community-dwelling older adults using self-report data. The Journals of Gerontology Series A: Biological Sciences and Medical Sciences, 59, M627-632.

Moayyeri, A., Hammond, C. J., Hart, D. J., \& Spector, T. D. (2013a). The UK adult twin registry (TwinsUK Resource). Twin Research and Human Genetics, 16, 144-149.

Moayyeri, A., Hammond, C. J., Valdes, M., \& Spector, T. D. (2013b). Cohort profile: TwinsUK and healthy ageing twin study. International Journal of Epidemiology, 42, 76-85.

Moreira, V. G., \& Lourenco, R. A. (2013). Prevalence and factors associated with frailty in an older population from the 
city of Rio de Janeiro, Brazil: The FIBRA-RJ study. Clinics (Sao Paulo), 68, 979-785.

Neale, M. C., Walters, E. E., Eaves, L. J., Maes, H. H., \& Kendler, K. S. (1994). Multivariate genetic analysis of twinfamily data on fears: Mx models. Behavior Genetics, 24, 119-139.

Needham, B. L., Smith, J. A., Zhao, W., Wang, X., Mukherjee, B., Kardia, S. L., ... Diez Roux, A. V. (2015). Life course socioeconomic status and DNA methylation in genes related to stress reactivity and inflammation: The multi-ethnic study of atherosclerosis. Epigenetics, 10, 958-969.

Office for National Statistics. (2005). The National Statistics Socio-Economic Classification. User Manual. London: Palgrave Macmillan.

Ortola, R., Garcia-Esquinas, E., Leon-Munoz, L. M., GuallarCastillon, P., Valencia-Martin, J. L., Galan, I., \& RodriguezArtalejo, F. (2016). Patterns of alcohol consumption and risk of frailty in community-dwelling older adults. The Journals of Gerontology Series A: Biological Sciences and Medical Sciences, 71, 251-258.

Peek, M. K., Howrey, B. T., Ternent, R. S., Ray, L. A., \& Ottenbacher, K. J. (2012). Social support, stressors, and frailty among older Mexican American adults. The Journals of Gerontology. Series B, Psychological Sciences and Social Sciences, 67, 755-764.

Peeters, H., Van Gestel, S., Vlietinck, R., Derom, C., \& Derom, R. (1998). Validation of a telephone zygosity questionnaire in twins of known zygosity. Behavior Genetics, 28, 159-163.

Preacher, K. J., \& Hayes, A. F. (2004). SPSS and SAS procedures for estimating indirect effects in simple mediation models. Behavior Research Methods, Instruments, and Computers, 36, 717-731.

Purdie, D. M., Dunne, M. P., Boyle, F. M., Cook, M. D., \& Najman, J. M. (2002). Health and demographic characteristics of respondents in an Australian national sexuality survey: Comparison with population norms. Journal of Epidemiology and Community Health, 56, 748-753.

Richardson, K., \& Norgate, S. (2005). The equal environments assumption of classical twin studies may not hold. British Journal of Educational Psychology, 75(Pt 3), 339-350.

Rockwood, K., Fox, R. A., Stolee, P., Robertson, D., \& Beattie, B. L. (1994). Frailty in elderly people: An evolving concept. Canadian Medical Association Journal, 150, 489-495.

Rockwood, R., Mitnitski, A., \& Howlett, S. E. (2015). Frailty: Scaling from cellular deficit accumulation? Interdisciplinary Topics in Gerontology and Geriatrics, 41, 1-14.

Romero-Ortuno, R. (2014). Frailty index in Europeans: Association with determinants of health. Geriatrics and Gerontology International, 14, 420-429.

Scarr, S. (1968). Environmental bias in twin studies. Eugenics Quarterly, 15, 34-40.

Searle, S. D., Mitnitski, A., Gahbauer, E. A., Gill, T. M., \& Rockwood, K. (2008). A standard procedure for creating a frailty index. BMC Geriatrics, 8, 24.
Spector, T. D., \& Williams, F. M. (2006). The UK adult twin registry (TwinsUK). Twin Research and Human Genetics, 9, 899-906.

Strawbridge, W. J., Shema, S. J., Balfour, J. L., Higby, H. R., \& Kaplan, G. A.(1998). Antecedents of frailty over three decades in an older cohort. The Journals of Gerontology Series B: Psychological Sciences and Social Sciences, 53, S9-S16.

Szanton, S. L., Seplaki, C. L., Thorpe, R. J. Jr, Allen, J. K., \& Fried, L. P. (2010). Socioeconomic status is associated with frailty: The women's health and aging studies. Journal of Epidemiology and Community Health, 64, 63-67.

Theou, O., Brothers, T. D., Pena, F. G., Mitnitski, A., \& Rockwood, K. (2014). Identifying common characteristics of frailty across seven scales. Journal of the American Geriatric Society, 62, 901-906.

Tishler, P. V., \& Carey, V. J. (2007). Can comparison of MZand DZ-twin concordance rates be used invariably to estimate heritability?. Twin Research and Human Genetics, 10, 712-717.

Trevisan, C., Veronese, N., Maggi, S., Baggio, G., De Rui, M., Bolzetta, F., ... Sergi, G. (2016). Marital status and frailty in older people: Gender differences in the Progetto Veneto Anziani longitudinal study. Journal of Women's Health, 25, 630-637.

United Nations Children's Emergency Fund (UNICEF) and World Health Organization (WHO). (2004). Low birthweight: Country, regional and global estimates. New York: UNICEF.

Van Den Beld, A., Huhtaniemi, I. T., Pettersson, K. S., Pols, H. A., Grobbee, D. E., De Jong, F. H., \& Lamberts, S. W. (1999). Luteinizing hormone and different genetic variants, as indicators of frailty in healthy elderly men. Journal of Clinical Endocrinology and Metabolism, 84, 1334-1339.

Walston, J., Arking, D. E., Fallin, D., Li, T., Beamer, B., Xue, Q., Ferrucci, L., ... Chakravarti, A. (2005). IL-6 gene variation is not associated with increased serum levels of IL-6, muscle, weakness, or frailty in older women. Experimental Gerontology, 40, 344-352.

Wang, C., Song, X., Mitnitski, A., Fang, X., Tang, Z., Yu, P., \& Rockwood, K. (2014). Effect of health protective factors on health deficit accumulation and mortality risk in older adults in the Beijing longitudinal study of aging. Journal of the American Geriatric Society, 62, 821-828.

Woo, J., Goggins, W., Sham, A., \& Ho, S. C. (2005). Social determinants of frailty. Gerontology, 51, 402-408.

Woods, N. F., LaCroix, A. Z., Gray, S. L., Aragaki, A., Cochrane, B. B., Brunner, R. L., Masaki, K., ... Newman, A. B. (2005). Frailty: Emergence and consequences in women aged 65 and older in the women's health initiative observational study. Journal of the American Geriatric Society, 53: 1321-1330. 